\title{
Transcription Abnormalities Potentiate Apoptosis of Normal Human Fibroblasts
}

\author{
Ladislav Andera and Bohdan Wasylyk \\ Institut de Génétique et de Biologie Moléculaire et Cellulaire, CNRS, \\ INSERM, ULP, Illkirch, France
}

\begin{abstract}
Background: Apoptosis is a natural process by which damaged and potentially tumorigenic cells are removed. Induction of apoptosis is important in chemotherapy aimed at eliminating cancer cells. We address the mechanisms by which this process can be triggered in cells that are recalcitrant to cell death induced by DNA-damaging agents.

Materials and Methods: Normal human fibroblasts and lymphoblasts, and fibroblasts with defined genetic changes, were treated with DNA-damaging agents and inhibitors of transcription. Western blotting was used to study the expression of some of the key factors involved in the response to DNA damage and the induction of apoptosis, namely, p53, p21 WAF1,Cip1, Mdm2, Bax, and CD95 (Fas/APO1). Apoptosis was followed by various criteria, including DNA fragmentation, specific proteolysis, cell morphology, viability, and FACS scan for sub-Gl cells.

Results: Normal human fibroblasts were more resistant than lymphoblasts to DNA damage-induced apoptosis.
\end{abstract}

The DNA-damaging agents mitomycin $\mathrm{C}$ and cisplatin induced rapid apoptosis of fibroblasts with defects in the repair of transcribed DNA, compared with wild-type cells or those with defects in overall genome repair. Shortterm treatment with inhibitors of RNA polymerase II transcription, actinomycin $\mathrm{D}$, and $\alpha$-amanitin induced rapid cell death of normal fibroblasts. These results show that there is a link between defective transcription and apoptosis. Treatments and genetic backgrounds that favored apoptosis were associated with efficient and prolonged induction of p53 and often altered or imbalanced expression of its downstream effectors p21 $1^{\text {WAF1,Cip1 }}$ and Mdm2, whereas there were no changes in Bax or CD95 (Fas/APOl).

Conclusion: Transcription inhibitors increase p53 levels and are better inducers of apoptosis than DNA-damaging agents in some cell types. Apoptosis might be triggered by blocked polymerases and/or faulty expression of downstream effectors.

\section{INTRODUCTION}

Premalignant and aberrant cells are eliminated by mechanisms involving the tumor suppressor p53 (1-5). A variety of cellular stresses, such as damaged DNA, viral infection, hypoxia, and depletion of ribonucleotides pool, can trigger posttranslational stabilization and activation of $\mathrm{p} 53$ (6-11). Activated p53 suppresses cellular growth through induction of either growth arrest $(12,13)$ and/or apoptosis $(1,14)$.

The mechanisms of p53-mediated growth ar-

Ladislav Andera's present address is Institute of Molecular Genetics, Laboratory of Leukocyte Antigens, Videnska 1083, 14220 Praha 4, Czech Republic.

Address correspondence and reprint requests to: $\mathrm{Dr}$. Bohdan Wasylyk, IGBMC, 1 rue Laurent Fries, B.P. 163, 67404 Illkirch, France. Tel: (33) 3886534 11; Fax: (33) 3 886532 46; E-mail: boh@igbmc.u-strasbg.fr rest are fairly well understood and are essentially mediated by transactivation of the gene for the cyclin-dependent kinase inhibitor (CKI) p2 $1^{\text {WAF1,Cipl }}(15)$. Wild-type p53 is also required for Gasl- and c-Abl-mediated growth suppression (16-18). Less well understood are the mechanisms of p53-induced apoptosis, its major tumor-suppressing function (19-23). p53 induces apoptosis through both transcription-dependent $(24,25)$ and -independent mechanisms (26-29). A transcription-independent apoptotic pathways could involve interactions between p53 and transcription/repair factor TFIIH $(28,30,31)$. Transcription-dependent pathways include regulation of the genes for $\mathrm{Bax}, \mathrm{Bcl}-2$, the death receptor CD95 (Fas/APO-1), and the $m d m 2$ proto-oncogene (32-36).

Up-regulation of pro-apoptotic Bax and 
TABLE 1. Human primary cells

\begin{tabular}{llc}
\hline Name & \multicolumn{1}{c}{ Description } & $\begin{array}{c}\text { Passage } \\
\text { No. }\end{array}$ \\
\hline GM01953B & Normal lymphoblasts & \\
GM03348C & Normal fibroblasts & $11-15$ \\
CS3BE & CSA fibroblasts & $21-24$ \\
CS1AN & CSB fibroblasts & $15-18$ \\
GM02995 & XPC fibroblasts & $7-10$ \\
GM03248 & XPD fibroblasts & $6-9$ \\
GM03021B & XPG fibroblasts & $12-15$ \\
& & \\
\hline
\end{tabular}

down-regulation of anti-apoptotic Bcl-2 sensitizes certain cell types to apoptotic stimuli $(32,37,38)$. $\gamma$-irradiation of mice leads to $\mathrm{p} 53$ dependent up-regulation of Bax and apoptosis only in T lymphocytes and epithelial cells of the small intestine (39). In contrast to Bax, Mdm2 inhibits $\mathrm{p} 53$-mediated apoptosis through binding to the $\mathrm{N}$-terminal transactivation domain $(40,41) \cdot p 53$ is involved in apoptosis of cell types other than thymocytes and epithelia. Fibroblasts from p53 knock-out mice are resistant to various DNA-damaging agents compared with wild-type (42). Rapid stabilization of p53 is associated with the high sensitivity of DNA repair-deficient xeroderma pigmentosum (XP) and Cockayne's syndrome (CS) fibroblasts to certain DNA-damaging agents $(43,44)$.

In this study, we investigated the factors that increase the sensitivity of fibroblasts to apoptosis. We have found that factors that affect transcription sensitize fibroblasts to apoptosis, including transcription inhibitors and genetic changes that affect transcription-coupled DNA repair. We discuss the possibilities that apoptosis might be triggered by either direct effects of blocked polymerase on p53 and/or faulty expression of downstream effectors. Understanding the mechanisms by which apoptosis can be triggered in recalcitrant cells could greatly help in pathological situations in which therapeutic approaches are aimed at triggering apoptosis.

\section{MATERIALS AND METHODS}

\section{Cells, Chemicals, and Treatments}

Human primary untransformed lymphoblasts and fibroblasts (Table 1) were either purchased from NIGMS Human Genetic Mutant Cell Repos- itory (Coriell Institute) or they were kindly provided by N. Jaspers and J. H. Hoeijmakers (CS strains). Cells were grown either in RPMI (lymphoblasts) or in Dulbecco's modified Eagle's medium (fibroblasts), supplemented with $15 \%$ fetal calf serum (FCS), nonessential amino acids, vitamins, and antibiotics at $37^{\circ} \mathrm{C}$ in humidified tissue culture incubators with $5 \% \mathrm{CO}_{2}$. Actinomycin D, $\alpha$-amanitin, cisplatin, 5,6-dichloro-1beta-D-ribofuranosyl-benzimidazole (DRB), mitomycin C, and MTT were purchased from Sigma. Cells were treated with drugs dissolved in the growth medium at the indicated concentrations, either continuously, or for $12 \mathrm{hr}$, in which case they were washed, reefed with fresh medium without drugs, and incubated further for the indicated times. Cell samples were taken at various times and analyzed for protein expression or apoptosis by different criteria.

\section{Antibodies, Gel Electrophoresis, and Immunodetection}

Harvested cells were lysed by heating to $95^{\circ} \mathrm{C}$ for 5 min in SDS electrophoresis loading buffer containing $1 \mathrm{mM} \mathrm{CaCl}_{2}$. Equal quantities of protein, determined by the Biorad protein assay, were electrophoresed on SDS gels and transferred to nitrocellulose membranes which were probed with appropriate antibodies followed by enhanced chemiluminescence (ECL) reagents (Amersham). Western blots were reprobed with antiTBP monoclonal antibodies (3G3, Y. Lutz, IGBMC) to verify equal loading. The different antibodies used were DO-1 (p53; 45), 826PAb (Mdm2, rabbit serum containing antibodies against $\mathrm{N}$-terminal 220 amino acids of human Mdm2), 590PAb and 592PAb (p21 $1^{\text {WAF1,Cipl }}$ purified rabbit antibodies recognizing $\mathrm{p} 21^{\mathrm{WAFI}}$,CIP1 synthetic peptides amino acids 81-98 and 131148, respectively), N20 (Bax, Santa Cruz Biotechnology) and C-20 (CD 95 [Fas/APO-1], Santa Cruz Biotechnology). Apoptosis-connected proteolytic cleavage of poly-(ADP ribosylase) polymerase (PARP; 46) was detected with aF2 polyclonal antibodies that recognize fulllength PARP and its 25 -kDa N-terminal proteolytic fragment (kindly provided by G. de Murcia). A 23-kDa proteolytic fragment of an unknown $42-\mathrm{kDa}$ protein, which is abundant in fibroblasts but undetectable in lymphoblasts, was recognized by the 592PAb antibodies. Proteolytic cleavage of the 42-kDa protein was found to be a marker of apoptosis from studies in CHP234 neuroblastoma cells, where it occurred at the same 
time as PARP cleavage (data not shown), and from comparisons with other criteria of apoptosis in fibroblasts (morphology, fluorescence-activated cell sorting [FACS] scanning and cleavage of chromosomal DNA, data not shown).

\section{DNA Extraction and Cell Viability Assays}

Cells used for extraction of low- to mediummolecular-weight DNA that appears during apoptosis were washed with phosphate-buffered saline (PBS) and permeabilized with DNA extraction buffer (47). Extracted extrachromosomal DNA was treated with phenol/chloroform, ethanol precipitated, separated in $1 \%$ agarose gels, and stained with ethidium bromide.

Drug-induced changes in cell viability were determined by the Triazolyl blue assay (MTT assay; 48). Relative cell viability that reflected the number of living cells was calculated as the ratio of $\left(\mathrm{A}_{570}: \mathrm{A}_{630}\right)$ at different times to time zero. Average values from two independent experiments were plotted against time.

\section{RESULTS}

\section{Primary Lymphoblasts and Fibroblasts Differ in Their Sensitivity to DNA Damage}

DNA damage stabilizes wild-type p53 and leads to growth arrest and, in some cases, apoptosis. We compared the effects of the DNA cross-linking anti-cancer agent, mitomycin $\mathrm{C}$, on induction of p53, p2 $1^{\text {WAF1,Cip1 }}$ with apoptosis of normal primary lymphoblasts and fibroblasts. The cells were continuously treated with $10 \mu \mathrm{M}$ mitomycin $\mathrm{C}$ and at various times samples were analyzed by Western blotting, DNA gel electrophoresis, and FACS scanning (Fig. 1). There were marked differences in the effects on the two cell types. p53 protein levels increased more rapidly in lymphoblasts than in fibroblasts (Fig. 1A; equal amounts of total protein were analyzed and loading was verified by reprobing for TBP, not shown). However, the p53-inducible cyclindependent kinase inhibitor (CKI) p2 $1^{\text {WAFl,Cipl }}$ was not induced in lymphoblasts but increased with similar kinetics as p53 in fibroblasts. The lack of p2 $1^{\text {WAF1,Cipl }}$ induction in lymphoblasts was correlated with an increased sensitivity to apoptosis, as shown by a number of criteria, including extractable extrachromosomal DNA, proteolytic cleavage, cells with a sub-Gl complement of DNA, and morphology. With lympho-
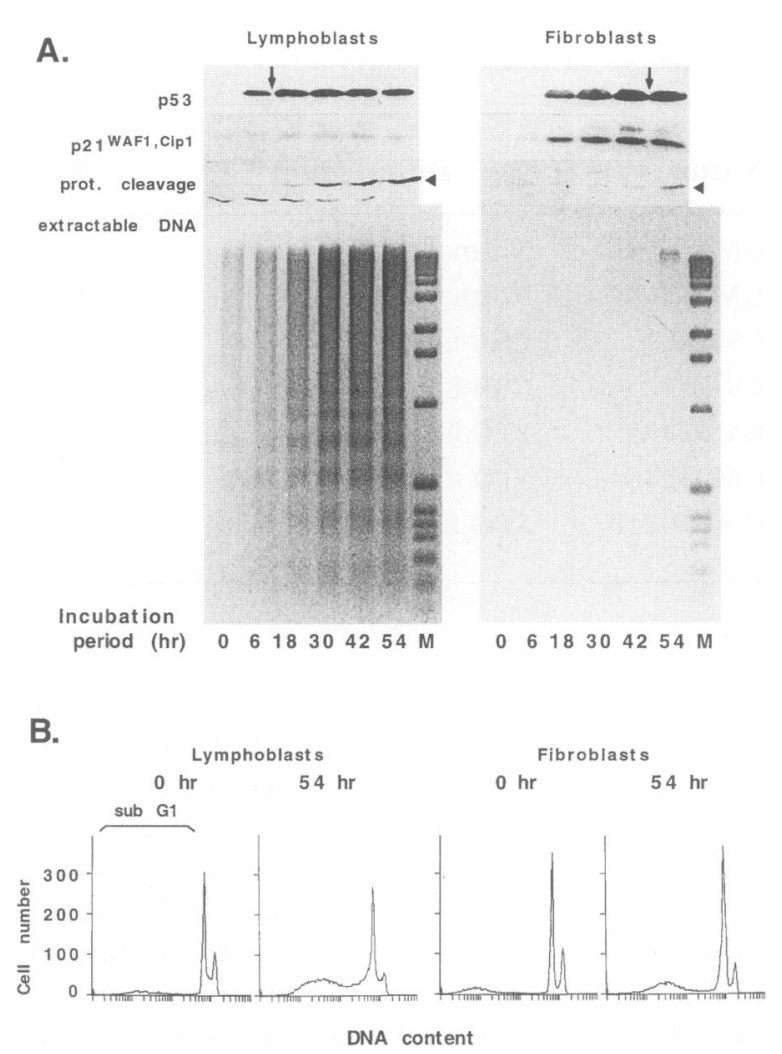

FIG. 1. Induction of p53 and apoptosis in normal primary B lymphoblasts and fibroblasts

Cell cultures were continuously treated with $10 \mu \mathrm{M}$ mitomycin $\mathrm{C}$, combined samples of both attached and floating cells were taken at the indicated time points, and analyzed. (A) Western blots of wholecell extracts were probed with antibodies recognizing

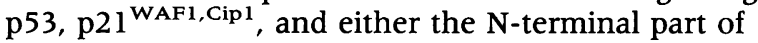
PARP (lymphoblasts) or a $42-\mathrm{kDa}$ protein (fibroblasts) (see Materials and Methods). Arrowheads point to the $25-\mathrm{kDa}$ fragment of PARP and the 23$\mathrm{kDa}$ fragment of a $42-\mathrm{kDa}$ protein that are cleavage products generated during apoptosis. Cells were also analyzed for extractable DNA (negatives of representative agarose gels are shown). Arrows above the p53 immunoblots indicate the time when the first signs of apoptosis (presence of extractable DNA, apoptosis-related proteolytic cleavage, and changes in cell morphology) were detected. $M, 1-\mathrm{kb}$ ladder (Gibco BRL). (B) Cell cycle analysis of treated cells at indicated time points. DNA content is shown on a logarithmic scale. The sub-Gl area contains apoptotic cells.

blasts, there was an increase after $6-18 \mathrm{hr}$ of nucleosomal ladder-sized DNA (Fig. 1A). With fibroblasts, there was an increase after $54 \mathrm{hr}$ of larger fragmented DNA, another sign of apoptosis (see the bands larger than the biggest $12-\mathrm{kb}$ marker in Fig. 1A) (44,49). Proteolytic cleavage of PARP was detected by 6-18 hr in lympho- 
blasts (see the 25-kDa fragment in Fig. 1A) and of a $42-\mathrm{kDa}$ protein after $54 \mathrm{hr}$ in fibroblasts (see the 23-kDa cleavage product in Fig. 1A and also Materials and Methods). FACS scan analysis after $54 \mathrm{hr}$ showed that there was an increase in the proportion of cells with a sub-Gl content of DNA, which accounted for about $50 \%$ of the total for lymphoblasts and $10 \%$ for fibroblasts (Fig. 1B). Visually, there were more "blebbing cells" with condensed nuclei among the lymphoblasts than the fibroblasts (not shown). These results show that although mitomycin $C$ induced p53 in both lymphoblasts and fibroblasts, the consequences for the two cell types was very different, in that fibroblasts were much more resistant to apoptosis. This could be related to the induction of p2 $1^{\text {WAF1,Cipl }}$ in fibroblasts but not in lymphoblasts (see below). We then investigated drug treatments and genetic changes that might favor apoptosis in fibroblasts.

\section{Apoptosis Induced by DNA Damage Is Faster in Cells with Deficiencies in Transcription-Coupled DNA Repair}

DNA repair-deficient cells, such as xeroderma pigmentosum (XP) or Cockayne's syndrome (CS) fibroblasts, are known to be more sensitive to various DNA-damaging agents than normal fibroblasts. We examined human primary fibroblasts with known deficiencies in DNA repair (Table 1). They were treated with mitomycin C and analyzed for the induction of p53, p2 $1^{\text {WAFl,Cipl }}$, and apoptosis, as described above. XPG fibroblasts, which are deficient in both transcription-coupled and overall DNA repair, induced p53 faster than did normal fibroblasts (compare Fig. 2A with Fig. 1A). The onset of apoptosis was about $24 \mathrm{hr}$ faster than in the normal fibroblasts, as judged by protein cleavage, DNA gel electrophoresis, and visually (Fig. 2A and data not shown). p2 $1^{\text {WAFl,Cipl }}$ protein levels increased with kinetics similar to p53 but then declined at later times (Fig. 2A). All the primary fibroblasts that were deficient in transcriptioncoupled DNA repair (CS, XPD, XPG) responded to mitomycin $C$ treatment with fast stabilization of 553 protein and rapid apoptosis (Fig. $2 \mathrm{~B}$, the onset of apoptosis was determined as in Figs. 1A and $2 \mathrm{~A}$ and is marked by arrows above the p53 immunoblots). In contrast, XPC fibroblasts, which are deficient in overall genome DNA repair, showed kinetics of $\mathrm{p} 53$ induction and resistance to mitomycin $C$ that were similar to that of normal fibroblasts (compare normal and XPC
A.

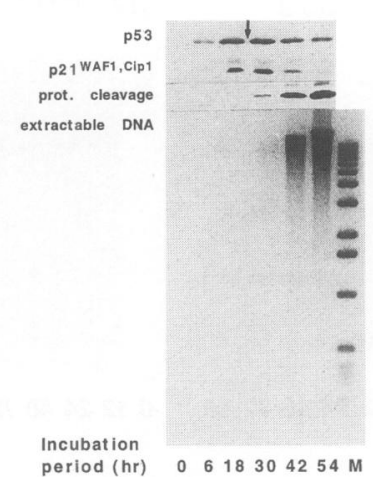

B.

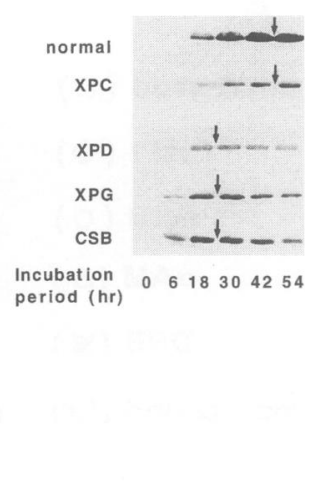

FIG. 2. p53 induction and apoptosis in DNA repair-deficient fibroblasts

Cells were treated with $10 \mu \mathrm{M}$ mitomycin $\mathrm{C}$ and samples were collected at the indicated time points. (A) Extracts of XPG fibroblasts were analyzed for p53 and p2 $1^{\text {WAF1,Cipl }}$ protein levels, apoptosis-connected proteolytic cleavage of a $42-\mathrm{kDa}$ protein, and for the presence of extractable DNA, as described for normal fibroblasts in Figure 1. (B) Kinetics of p53 induction and apoptosis in mitomycin C-treated primary fibroblasts. Cell samples were analyzed as in A, but only the p53 immunoblots are shown. Arrows indicate the time when first signs of apoptosis were detected, as in Figure 1. M, migration of the $1-\mathrm{kb}$ ladder.

lanes in Fig. 2B). Sensitivity to apoptosis seemed to be correlated with the kinetics of p53 induction rather than absolute levels, possibly because the amount of p53 does not reflect activity or that additional factors are involved (note that equal amounts of total protein were analyzed). These results show that deficiencies in transcription-coupled DNA repair rather than overall genome DNA repair increase the rate of apoptosis in fibroblasts.

\section{Transcription Inhibitors Induce Apoptosis of Normal Fibroblasts}

DNA damage in transcribed DNA could stimulate apoptosis through inhibition of transcription. In this case, inhibitors of transcription might be efficient inducers of apoptosis in normal fibroblasts. We compared the effects of inhibitors of transcription (actinomycin D, $\alpha$-amanitin, and DRB) and a DNA-damaging agent (cisplatin) on fibroblasts. A short-term treatment was used to study the reaction and the recovery from the effects of the inhibitors. The cells were treated for $12 \mathrm{hr}$, washed to remove the excess of inhibitors or DNA-damaging agent, and, after various 


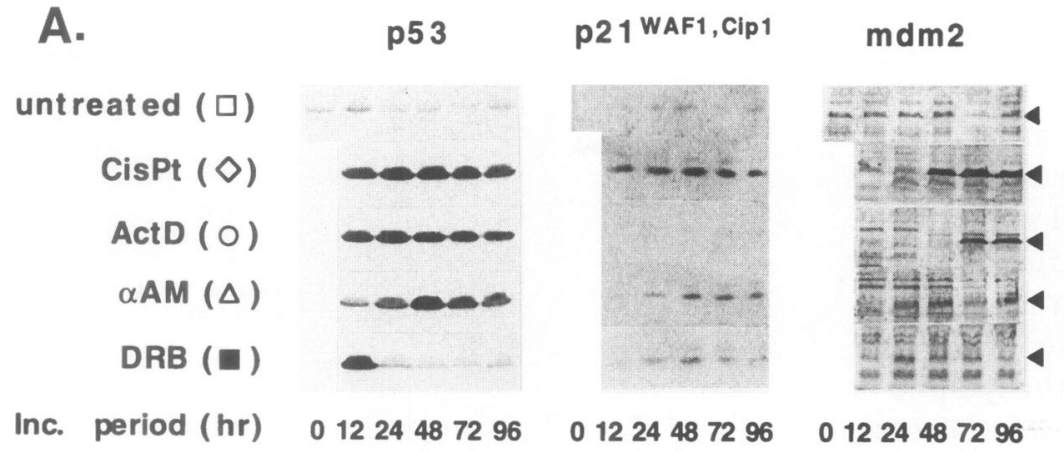

B.

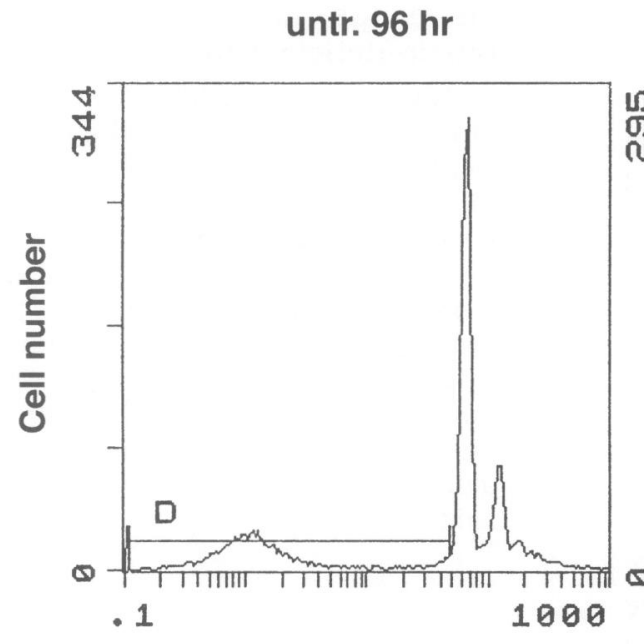

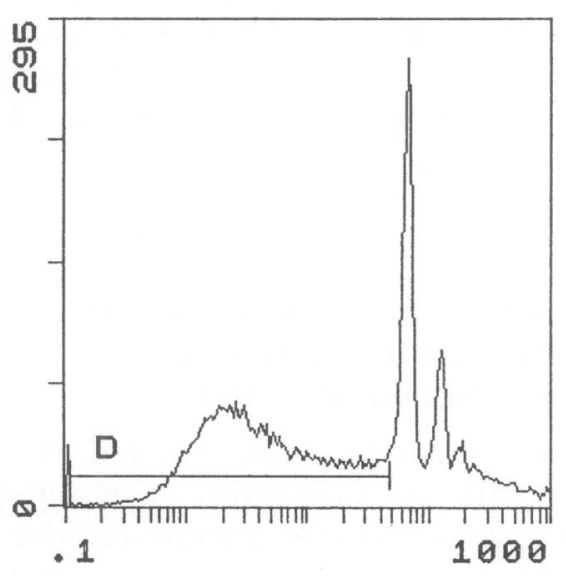

DNA content

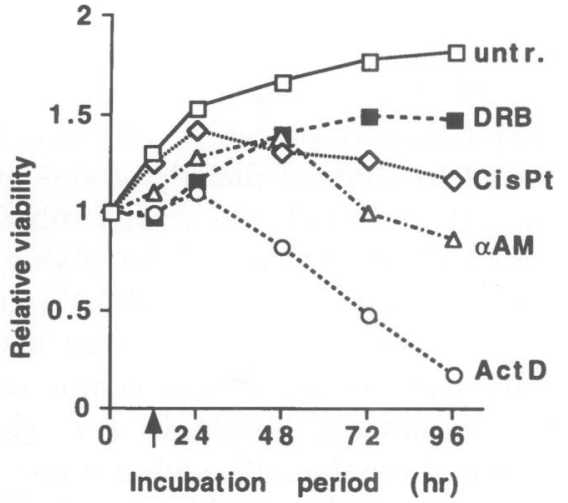

ActD $96 \mathrm{hr}$

FIG. 3. Effects of DNA-damaging drugs and inhibitors of transcription on the viability of normal human fibroblasts and expression of $\mathrm{p} 53$ and its effectors

Human primary fibroblasts (GM03348C) were treated with medium only (untreated, untr.) or with medium containing cisplatin (CisPt, $10 \mu \mathrm{M})$, actinomycin D (ActD, $0.4 \mu \mathrm{M}), \alpha$-amanitin $(\alpha \mathrm{AM}, 1 \mu \mathrm{M})$, and DRB (DRB, 100 $\mu \mathrm{M}$ ) for $12 \mathrm{hr}$ (marked by an arrow on the $\mathrm{x}$-axis of the cell viability graph). The cells were then washed, refed with fresh medium, and incubated for $84 \mathrm{hr}$ more. Cell samples for protein analysis (A, Western blots on the left side of the figure), MTT-based cell viability assays (A, graph on the right side of the figure) and FACS scan analysis (B) were harvested at the indicated time points. Equal amounts of total protein were loaded onto SDS polyacrylamide gels and Western blots were probed with antibodies that recognize p53, p2 ${ }^{\text {WAF1,Cip1 }}$, and Mdm2 (only the corresponding parts of the Western blots are shown). Arrowheads on the right side of Mdm2 Western blots indicate $\mathrm{Mdm} 2$. The values in the cell viability graphs are averages from two independent experiments with a difference of less than $20 \%$. (B) Cell cycle analysis of untreated (untr.) and actinomycin D (ActD)-treated cells after 96 hr. DNA content is shown on a logarithmic scale. The sub-Gl area (D) contains apoptotic cells.

times, were analyzed for p53 expression by Western blotting and for viability by the MTT cell proliferation assay. The MTT assay was found to be the most efficient and reproducible method to quantify apoptosis, with variations between experiments of less than $20 \%$. We confirmed that the cells were undergoing apoptosis by FACS scan analysis, specific proteolysis, DNA fragmentation, and morphology (see below for actinomy- cin D and data not shown). Cisplatin induced fast stabilization of p53 (Fig. 3A). However, even after $84 \mathrm{hr}$ ( $96 \mathrm{hr}$ of total incubation), the majority of the cells were viable (Fig. $3 \mathrm{~A}$, see the graph on the right). Actinomycin D also induced fast stabilization of $\mathrm{p} 53$ with similar kinetics, but the cells died rapidly of apoptosis, as quantitated by the MTT assay (Fig. 3A). As expected from apoptosis, the number of cells with a sub-Gl 
content of DNA increased dramatically (Fig. 3B, $15 \%$ in untreated cells, $60 \%$ in treated cells after $96 \mathrm{hr}$ ). $\alpha$-Amanitin induced p53 more slowly but still stimulated apoptosis more efficiently than cisplatin. DRB induced a transient burst of p53, with little consequence for cell survival. These results show that transcription inhibitors that induce prolonged stabilization of $\mathrm{p} 53$ can trigger apoptosis more efficiently than the DNA-damaging agent cisplatin in fibroblasts.

\section{Altered Expression of Downstream Effectors of p53 Is Associated with Induction of Apoptosis in Normal Fibroblasts}

Transcription inhibitors may affect the expression of genes that are normally stimulated by $\mathrm{p} 53$ in response to DNA damage. Western blots were used to analyze the expression of $\mathrm{p} 21^{\mathrm{WAFl}, \mathrm{Cipl}}$, Mdm2 (Fig. 3A), Bax, and Fas/APO-1 (not shown). Cisplatin induced rapid accumulation of p53, closely followed by $21^{\text {WAFl,Cipl }}$, and later Mdm2 (Fig. 3A, see untreated samples for the zero time points for all samples). In contrast, actinomycin D, which also rapidly induced p53, had only a small and barely detectable effect on

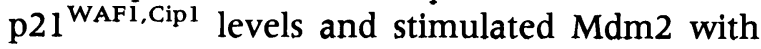
delayed kinetics. $\alpha$-Amanitin induced p53 and p2 $1^{\text {WAF1,Cipl }}$ with delayed kinetics and Mdm2 levels hardly varied. DRB produced a transient burst of p53 followed by a slight increase in p2 $1^{\text {WAFI,Cipl }}$ and little change in Mdm2. Bax and Fas/APO-1 levels were not altered by any of the treatments (data not shown). These results correlate induction of apoptosis by transcription inhibitors with altered expression of the effectors p2 $1^{\text {WAFl,Cipl }}$ and Mdm2.

\section{Transcription-Coupled DNA Repair Deficiency Alters the Response to Transcription Inhibitors}

Deficiency in transcription-coupled DNA repair sensitizes fibroblasts to DNA damage induced apoptosis, suggesting that it may also affect the outcome of inhibition of transcription. Cockayne's syndrome A and B (CSA and CSB) fibroblasts were treated with cisplatin and the transcription inhibitors for $12 \mathrm{hr}$, washed, and analyzed for induction of p53, p2 $1^{\text {WAF1,Cipl, }}$ Mdm2, and cell survival, as described above. Cisplatin induced rapid accumulation of p53 and fast induction of $\mathrm{p} 21^{\text {WAFl,Cipl }}$ and Mdm2, which decreased later when the cells died (Fig. 4, see untreated samples for the zero time points for all samples). Actinomycin D also induced p53 with similar kinetics. However, there was delayed but sustained induction of $\mathrm{p} 21^{\mathrm{WAFl}, \mathrm{Clpl}}$ and Mdm2, reminiscent of normal fibroblasts treated with cisplatin, and the cells survived. $\alpha$-Amanitin consistently had little effect on CSA fibroblasts. In contrast, with CSB, it induced p53 and cell death and a much attenuated response at the level of p21 ${ }^{\text {WAFl,Cipl }}$ and Mdm2. DRB induced a transient burst of p53, a weak response at the level of p2 $1^{\text {WAFl,Cipl } 1}$ and Mdm2, and little effect on cell survival, a response similar to that in normal fibroblasts. These results show that sensitivity to apoptosis is correlated with altered kinetics of induction of $\mathrm{p} 53$ and its effectors p21 $1^{\text {WAF1,Cipl }}$ and $M d m 2$. The differences in kinetics were reproducibly observed in different experiments (note that one representative experiment is shown for the Western blots in Fig. 4). Induction of pro-apoptotic Bax and Fas/APO-1 have been shown to be mediated by $\mathrm{p} 53$ under certain conditions $(33,38)$. However, we did not observe up-regulation of either Bax or Fas/APO-1 proteins in any of the drug-treated fibroblasts strains (data not shown). These results show that transcription-coupled DNA repair deficiency alters the response to transcription inhibitors, which suggests that they are interconnected rather than independent processes.

\section{DISCUSSION}

We have examined an important question relating to both normal cellular functions and the treatment of pathologies such as cancer: what makes a cell more or less sensitive to induction of apoptosis. We have found an interesting link between defects in transcription and induction of apoptosis. Furthermore, we found that inhibitors of transcription induce accumulation of $\mathrm{p} 53$.

p53 protein levels are usually low in normal cells and increase in response to various stress signals. The best characterized signal is DNA damage of various forms (4); others are hypoxia (50) and depletion of ribonucleotide triphosphate pools (11). We show that p53 levels rise in response to transcription inhibitors and cell death is associated with prolonged induction of p53, as would be expected for p53 monitoring of correct transcription that is required for normal progression through the cell cycle.

Normal B lymphoblasts are more sensitive than primary fibroblasts to the DNA-damaging 

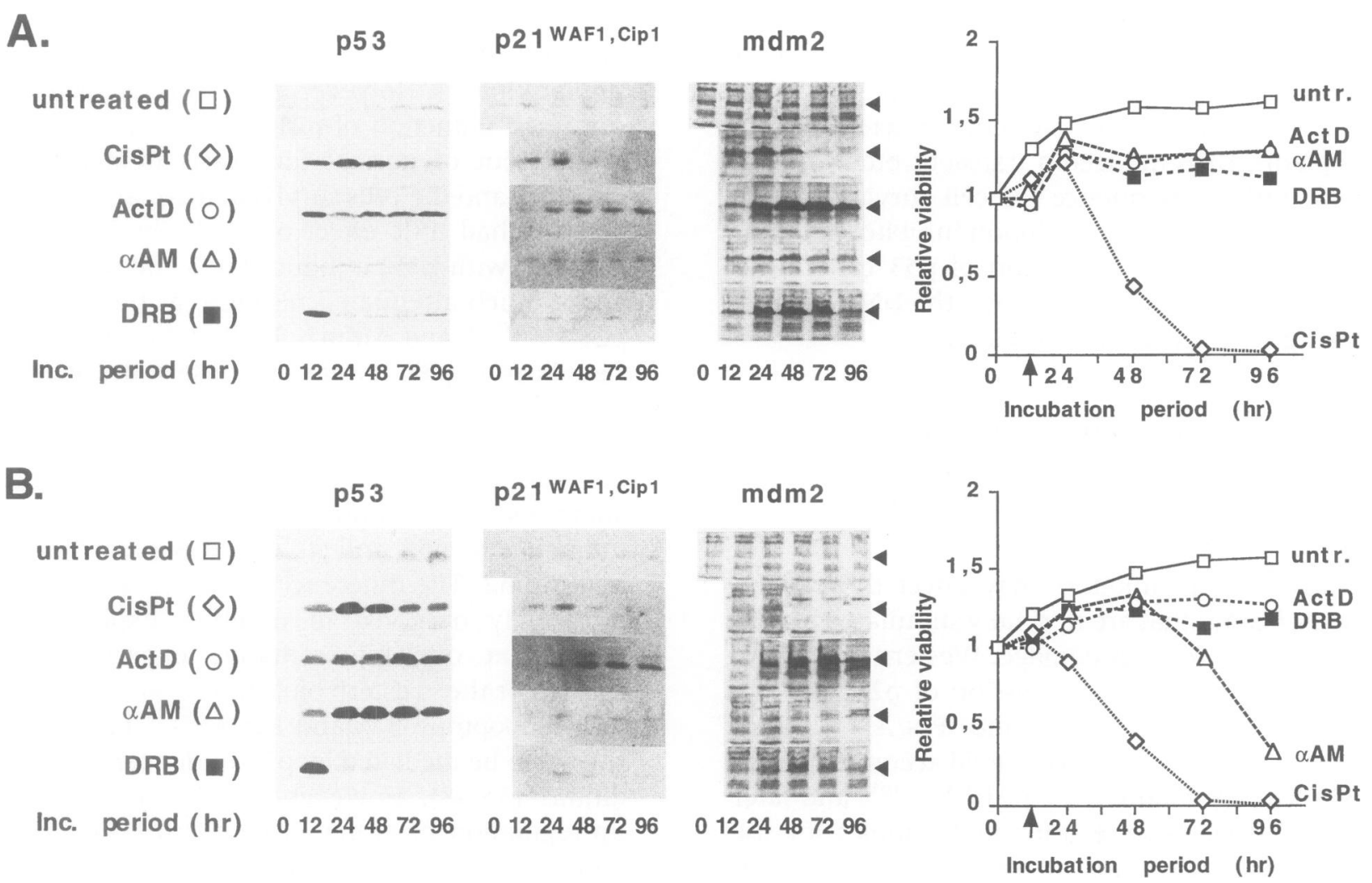

FIG. 4. Effects of DNA-damaging drugs and inhibitors of transcription on the viability of Cockayn's syndrome fibroblasts and induction of $\mathrm{p} 53$ and its effectors

Cockayn's syndrome A (CS3BE) (A) and B (CS1AN) (B) fibroblasts were treated and analyzed as described for normal fibroblasts in the legend of Figure 3. The values in the cell viability graphs are averages for two independent experiments.

agents mitomycin $\mathrm{C}$ and cisplatin, which trigger rapid accumulation of $\mathrm{p} 53$ and apoptosis. Proliferating EBV-transformed B cells are known to be sensitive to DNA-damaging agents but growthstimulated primary B lymphoblasts are apparently resistant to cisplatin treatment $(51,52)$. The B lymphoblasts that were used in our experiments were not transformed with EBV but still readily underwent apoptosis after challenge with mitomycin C. Their sensitivity to DNA-damaging drugs could be connected with their inability to induce $\mathrm{p} 21^{\text {WAF1, Cip } 1}$ expression (see below).

Primary fibroblasts with defined genetic alterations in DNA repair pathways helped us to identify factors that participate in induction of apoptosis. The resistance of fibroblasts to apoptosis is not simply related to the extent of DNA damage. XPC fibroblasts, which are deficient in repair of transcriptionally silent DNA but not in transcription-coupled DNA repair, are as resistant to DNA damage induced apoptosis as normal fibroblasts. These results are in apparent contra- diction with their poor clonogenic survival after UV treatment (43). A possible explanation is that unrepaired DNA maintains higher levels of $\mathrm{p} 53$ and extended growth arrest, which prevents colony formation but not survival. XPD, XPG, and CS fibroblasts, which are deficient in transcription-coupled DNA repair, underwent rapid apoptosis when treated with mitomycin $\mathrm{C}$ or cisplatin. Apoptosis may be triggered by the persistence of damage to essential genes or by the failure to restore RNA synthesis $(43,44)$. CS fibroblasts are deficient in transcription (53-55) as well as transcription-coupled DNA repair $(56,57)$, both of which may influence their response to DNA-damaging agents. Defects in transcription may signal cell death in the absence or presence of DNA damage and may also have effects through altered expression of downstream targets of $\mathrm{p} 53$.

The kinetics of $\mathrm{p} 53$ induction and expression of its target genes $p 21^{W A F l, C i p I}, \operatorname{mdm} 2, B a x$, and Fas/APO-1 were compared in treated cells. Bax 
and Fas/APO-l have been shown to be p53inducible in ML-1 and BRK cells (Bax; 38,58) and in an adenocarcinoma cell line (Fas; 33). However, their levels did not changed in any of the fibroblasts strains and most probably did not contribute to induction of apoptosis. We observed that sensitivity to apoptosis of fibroblasts and lymphoblasts was associated with prolonged induction of $\mathrm{p} 53$ often accompanied by altered expression of either $\mathrm{p} 21^{\mathrm{WAF} 1, \mathrm{Cip} 1}, \mathrm{Mdm} 2$, or both. There are a number of examples. Actinomycin D treatment of normal fibroblasts (Fig. 3A) leads to cell death and a rapid increase in p53 that is not accompanied by the increases in $\mathrm{p} 21^{\mathrm{WAF1}, \mathrm{Cip} 1}$ or Mdm2 seen in cells resistant to apoptosis, such as normal fibroblasts treated with cisplatin (Fig. 3A) or CSA, or CSB fibroblasts treated with actinomycin D (Fig. 4). Mitomycin $\mathrm{C}$ treatment of lymphoblasts induces apoptosis and $\mathrm{p} 53$ with no increase in p21 $1^{\text {WAFl,Cipl, }}$ whereas treatment of fibroblasts does not induce cell death but upregulates both p53 and p2 $1^{\text {WAF1,Cipl }}$. There is a graded response to $\alpha$ amanitin in that there is extensive cell death when $\mathrm{p} 53$ is induced strongly, but p21 $1^{\text {WAF1,Cip } 1}$ and $\mathrm{Mdm} 2$ are hardly detectable (CSB, Fig. 4B); there is less cell death when there is a more pronounced increase in $\mathrm{p} 21^{\mathrm{WAF} 1, \mathrm{Cip} 1}$ and $\mathrm{Mdm} 2$ (normal fibroblasts, Fig. 3A), which is nonetheless delayed compared with normal fibroblasts treated with cisplatin which survive (Fig. 3A). Apoptosis has always been associated with an increase in p53. For example, $\alpha$-amanitin stimulated p53 and apoptosis in CSB, but did not affect p53 levels nor stimulate apoptosis in CSA (Fig. 4). However, high p53 levels per se were not sufficient to induce apoptosis. The rapidity rather than the level of p53 induction was correlated with the sensitivity of repair-deficient cells to apoptosis induced by mitomycin $C$ (see Fig. 2). Equivalent amounts of p53 were induced in cisplatin- and actinomycin D-treated CSA and CSB fibroblasts (Fig. 4), but only cisplatin induced apoptosis. These results suggest that imbalances in the relative levels of induction of p2 $1^{\text {WAF1,Cipl }}$ and Mdm2 could affect p53's ability to induce apoptosis. Experiments are in progress to test this hypothesis, using antisense or HPV E6 to modulate the different effectors. Interestingly, rapid down-regulation of $\mathrm{p} 21^{\text {WAF1,Cip1 }}$ in Baf-3 cells after interleukin 3 (IL-3) withdrawal is associated with rapid apoptosis (59). Furthermore, several recent studies have shown that the proapoptotic function of $\mathrm{p} 53$ is inhibited by p2 $1^{\text {WAF1,Cipl }}$-mediated growth arrest $(25,60-63)$ and Mdm2 overexpression $(40,41)$. Mdm2 and p21 ${ }^{\text {WAFl,Cipl }}$ regulate the $\mathrm{p} 53$ and Rb pathways, respectively, and imbalances in the two pathways are associated with apoptosis (4).

Inhibition of transcription might trigger apoptotic functions of p53 that do not require transcription. It is possible that transcription complexes, stalled by DNA damage or inhibitors of transcription elongation (actinomycin D and $\alpha$ amanitin), recruit p53 and convert it to a proapoptotic form. p53 may be modified by components of the transcription and DNA repair machinery, such as the kinase associated with TFIIH. This working model is a framework for further experiments that explain our observations and the known properties of $\mathrm{p} 53$. Ljungman and Zhang (44) independently suggested that persistent transcription-blocking lesions, due to defective transcription-coupled repair, may trigger apoptosis. We show in addition that inhibitors of transcription can induce apoptosis. p53 has apoptotic functions that are distinct from transcription regulation. For example, p53 has an N-terminal proline-rich region that is required for growth suppression but not transcription $(64,65)$. We found that actinomycin D treatment leads to apoptosis of normal but not CSA or CSB fibroblasts. Both CSA and CSB proteins interact with TFIIH $(66,67)$, and CSB and TFIIH interact with p53 $(30,31)$; they could affect recruitment and modification of $\mathrm{p} 53$.

Stabilized p53 might not always be competent to induce apoptosis. Treatment of fibroblasts with DRB resulted in a strong increase in p53 protein levels but did not lead to apoptosis. DRB inhibits TFIIH-mediated phosphorylation of the C-terminal repeats of the largest subunit of RNA polymerase II and consequently, elongation of transcription (68). p53 interacts with TFIIH, and it is conceivable that the TFIIH kinase could directly (through phosphorylation of p53) (69) or indirectly (phosphorylation of an auxiliary factor) affect the proapoptotic function of $\mathrm{p} 53$. SAP kinases may also influence p53-mediated apoptosis, since they can phosphorylate the $\mathrm{N}$ terminus of p53 (70) and are connected with the induction of apoptosis $(71,72)$. Finally, downstream effectors of p53 could modulate its apoptotic functions: $\mathrm{p} 21^{\text {WAF1,Cipl }}$, by its ability to inhibit cyclin-dependent kinases that phosphorylate p53 $(73,74)$, and Mdm2, by complex formation $(40,41)$. Our results, in accordance with these studies, suggest that deregulation of the expression of the p53 target genes p21 WAF1,Cip1 and Mdm2, and possibly also phosphorylation of 
p53, could affect the ability of p53 to induce apoptosis in damaged or stressed cells.

In summary, a stressed transcriptional state in the cell may be a trigger for p53 and apoptosis in a manner similar to that in DNA damage or metabolism. Inhibitors of transcription may be useful in treatments aimed at inducing apoptosis of cells that are resistant to DNA-damaging agents.

\section{ACKNOWLEDGMENTS}

We are grateful to Jan H. Hoeijmakers, Nicholas J. Jaspers, David P. Lane, and Gilbert De Murcia for generously providing us with cells and antibodies and to Sagar Sengupta for kind help. We thank Thierry Léveillard and Sagar Sengupta for critical reading of the manuscript, members of the Gene Medecine Department of Rhone-Poulenc Rohrer (especially Bruno Tocque, Laurent Bracco, Laurent Debussche, and Emmanuel Conseiller) for continual help and encouragement, the staff of the IGBMC facilities for their invaluable help, and various funding agencies, including: the Centre National de la Recherche Scientifique, the Institut National de la Santé et de la Recherche Médicale, the Centre Hospitalier Universitaire Régional, the Association pour la Recherche sur le Cancer, the Fondation pour la Recherche Médicale, the Ligue Nationale Française contre le Cancer, the Ligue Régionale (Haut-Rhin) contre le Cancer, the Ligue Régionale (Bas-Rhin) contre le Cancer (the Legs Meyer), and the Bioavenir Program (Ministère de la Recherche et Ministère de l'Industrie).

\section{REFERENCES}

1. Bates S, Vousden KH. (1996) p53 in signaling checkpoint arrest or apoptosis. Curr. Opin. Genet. Dev. 6: 12-18.

2. Gottlieb TM, Oren M. (1996) p53 in growth control and neoplasia. Biochim. Biophys. Acta 1287: 77-102.

3. Ko LJ, Prives C. (1996) p53: puzzle and paradigm. Genes Dev. 10: 1054-1072.

4. Levine AJ. (1997) p53, the cellular gatekeeper for growth and division. Cell 88: 323331.

5. Hansen R, Oren M. (1997) p53; from inductive signal to cellular effect. Curr. Opin. Genet. Dev. 7: 46-51.

6. Kastan MB, Onyekwere O, Sidransky D, Vo- gelstein B, Craig RW. (1991) Participation of p53 protein in the cellular response to DNA damage. Cancer Res. 51: 6304-6311.

7. Lowe SW, Ruley HE. (1993) Stabilization of the p53 tumor suppressor is induced by adenovirus $5 \mathrm{ElA}$ and accompanies apoptosis. Genes Dev. 7: 535-545.

8. Lu X, Lane DP. (1993) Differential induction of transcriptionally active p53 following UV or ionizing radiation: Defects in chromosome instability syndromes? Cell 75: 765-778.

9. Zhan Q, Carrier F, Fornace AJ, Jr. (1993) Induction of cellular p53 activity by DNAdamaging agents and growth arrest [erratum appears in Mol. Cell. Biol. (1993) 13(9): 5928]. Mol. Cell. Biol. 13: 4242-4250.

10. Demers GW, Foster SA, Halbert CL, Galloway DA. (1994) Growth arrest by induction of p53 in DNA damaged keratinocytes is bypassed by human papillomavirus 16 E7. Proc. Natl. Acad. Sci. U.S.A. 91: 4382-4386.

11. Linke SP, Clarkin KC, Di Leonardo A, Tsou A, Wahl GM. (1996) A reversible, p53-dependent G0/Gl cell cycle arrest induced by ribonucleotide depletion in the absence of detectable DNA damage. Genes Dev. 10: 934947.

12. Kastan MB, Zhan Q, el-Deiry WS, et al. (1992) A mammalian cell cycle checkpoint pathway utilizing p53 and GADD45 is defective in ataxia-telangiectasia. Cell 71: 587-597.

13. Cross SM, Sanchez CA, Morgan CA, et al. (1995) A p53-dependent mouse spindle checkpoint. Science 267: 1353-1356.

14. Yonish-Rouach E, Resnitzky D, Lotem J, Sachs L, Kimchi A, Oren M. (1991) Wildtype p53 induces apoptosis of myeloid leukaemic cells that is inhibited by interleukin-6. Nature 352: 345-347.

15. El-Deiry WS, Tokino T, Velculescu VE, et al. (1993) WAFl, a potential mediator of p53 tumor suppression. Cell 75: 817-825.

16. Del Sal G, Ruaro EM, Utrera R, Cole CN, Levine AJ, Schneider C. (1995) Gasl-induced growth suppression requires a transactivation-independent $\mathrm{p} 53$ function. Mol. Cell. Biol. 15: 7152-7160.

17. Yuan ZM, Huang Y, Whang Y, et al. (1996) Role for c-Abl tyrosine kinase in growth arrest response to DNA damage. Nature 382: 272-274.

18. Wen ST, Jackson PK, Van Etten RA. (1996) The cytostatic function of $\mathrm{c}-\mathrm{Abl}$ is controlled by multiple nuclear localization signals and 
requires the $\mathrm{p} 53$ and $\mathrm{Rb}$ tumor suppressor gene products. EMBO J. 15: 1583-1595.

19. Symonds H, Krall L, Remington L, et al. (1994) p53-dependent apoptosis suppresses tumor growth and progression in vivo. Cell 78: 703-711.

20. Lowe SW, Jacks T, Housman DE, Ruley HE. (1994) Abrogation of oncogene-associated apoptosis allows transformation of p53-deficient cells. Proc. Natl. Acad. Sci. U.S.A. 91: 2026-2030.

21. Howes KA, Ransom N, Papermaster DS, Lasudry JG, Albert DM, Windle JJ. (1994) Apoptosis or retinoblastoma: Alternative fates of photoreceptors expressing the HPV-16 E7 gene in the presence or absence of $\mathrm{p} 53$ [erratum appears in Genes Dev. (1994) 8(14): 1738]. Genes Dev. 8: 1300-1310.

22. Morgenbesser SD, Williams BO, Jacks T, De Pinho RA. (1994) p53-dependent apoptosis produced by $\mathrm{Rb}$-deficiency in the developing mouse lens [see comments]. Nature 371: 7274.

23. Rowan S, Ludwig RL, Haupt Y, et al. (1996) Specific loss of apoptotic but not cell-cycle arrest function in a human tumor derived p53 mutant. EMBO J. 15: 827-838.

24. Sabbatini $P$, Lin J, Levine AJ, White E. (1995) Essential role for p53-mediated transcription in ElA-induced apoptosis. Genes Dev. 9: 2184-2192.

25. Attardi LD, Lowe SW, Brugarolas J, Jacks T. (1996) Transcriptional activation by $\mathrm{p} 53$, but not induction of the $p 21$ gene, is essential for oncogene-mediated apoptosis. $E M B O \mathrm{~J}$. 15: 3693-3701.

26. Caelles C, Helmberg A, Karin M. (1994) p53dependent apoptosis in the absence of transcriptional activation of p53-target genes [see comments]. Nature 370: 220-223.

27. Haupt Y, Rowan S, Shaulian E, Vousden $\mathrm{KH}$, Oren M. (1995) Induction of apoptosis in HeLa cells by trans-activation-deficient p 53 . Genes Dev. 9: 2170-2183.

28. Wang XW, Vermeulen W, Coursen JD, et al. (1996) The XPB and XPD DNA helicases are components of the p53-mediated apoptosis pathway. Genes Dev. 10: 1219-1232.

29. Chen X, Ko LJ, Jayaraman L, Prives C. (1996) p53 levels, functional domains, and DNA damage determine the extent of the apoptotic response of tumor cells. Genes Dev. 10: 2438-2451.

30. Wang XW, Yeh H, Schaeffer L, et al. (1995) p53 modulation of TFIIH-associated nucleo- tide excision repair activity. Nat. Genet. 10: 188-195.

31. Leveillard T, Andera L, Bissonnette N, et al. (1996) Functional interactions between p53 and the TFIIH complex are affected by tumour-associated mutations. EMBO J. 15: 1615-1624.

32. Miyashita T, Reed JC. (1995) Tumor suppressor p53 is a direct transcriptional activator of the human bax gene. Cell 80: 293-299.

33. Owen-Schaub LB, Zhang W, Cusack JC, et al. (1995) Wild-type human p53 and a temperature-sensitive mutant induce Fas/ APO-1 expression. Mol. Cell. Biol. 15: 30323040.

34. Muller M, Strand S, Hug H, et al. (1997) Drug-induced apoptosis in hepatoma cells is mediated by the CD95 (APO-1/Fas) receptor/ligand system and involves activation of wild-type p53. J. Clin. Invest. 99: 403-413.

35. Barak Y, Juven T, Haffner R, Oren M. (1993) $m d m 2$ expression is induced by wild-type p53 activity. EMBO J. 12: 461-468.

36. Perry ME, Piette J, Zawadzki JA, Harvey D, Levine AJ. (1993) The $m d m-2$ gene is induced in response to UV light in a p53-dependent manner. Proc. Natl. Acad. Sci. U.S.A. 90: 11623-11627.

37. Miyashita T, Krajewski S, Krajewska M, et al. (1994) Tumor suppressor p53 is a regulator of $b c l-2$ and $b a x$ gene expression in vitro and in vivo. Oncogene 9: 1799-1805.

38. Zhan Q, Fan S, Bae I, et al. (1994) Induction of bax by genotoxic stress in human cells correlates with normal p53 status and apoptosis [erratum appears in Oncogene (1995) 10(6): 1259]. Oncogene 9: 3743-3751.

39. Kitada S, Krajewski S, Miyashita T, Krajewska M, Reed JC. (1996) Gamma-radiation induces upregulation of Bax protein and apoptosis in radiosensitive cells in vivo. Oncogene 12: 187-192.

40. Chen J, Wu X, Lin J, Levine AJ. (1996) $m d m-2$ inhibits the Gl arrest and apoptosis functions of the p53 tumor suppressor protein. Mol. Cell. Biol. 16: 2445-2452.

41. Haupt Y, Barak Y, Oren M. (1996) Cell typespecific inhibition of p53-mediated apoptosis by $m d m 2$. EMBO J. 15: 1596-1606.

42. Lowe SW, Ruley HE, Jacks T, Housman DE. (1993) p53-dependent apoptosis modulates the cytotoxicity of anticancer agents. Cell 74: 957-967.

43. Yamaizumi M, Sugano T. (1994) UV-induced nuclear accumulation of $\mathrm{p} 53$ is 
evoked through DNA damage of actively transcribed genes independent of the cell cycle. Oncogene 9: 2775-2784.

44. Ljungman M, Zhang F. (1996) Blockage of RNA polymerase as a possible trigger for Uv light-induced apoptosis. Oncogene 13: 823831.

45. Vojtesek B, Bartek J, Midgley CA, Lane DP. (1992) An immunochemical analysis of the human nuclear phosphoprotein p53. New monoclonal antibodies and epitope mapping using recombinant p53. J. Immunol. Methods 151: $237-244$.

46. Kaufmann SH, Desnoyers S, Ottaviano Y, Davidson NE, Poirier GG. (1993) Specific proteolytic cleavage of poly(ADP-ribose) polymerase: An early marker of chemotherapy-induced apoptosis. Cancer Res. 53: 39763985.

47. Roy C, Brown DL, Little JE, et al. (1992) The topoisomerase II inhibitor teniposide (VM26) induces apoptosis in unstimulated mature murine lymphocytes. Exp. Cell Res. 200: 416-424.

48. Denizot F, Lang R. (1986) Rapid colorimetric assay for cell growth and survival. Modifications to the tetrazolium dye procedure giving improved sensitivity and reliability. J. Immunol. Methods 89: 271-277.

49. Oberhammer F, Wilson JW, Dive C, et al. (1993) Apoptotic death in epithelial cells: Cleavage of DNA to 300 and/or $50 \mathrm{~kb}$ fragments prior to or in the absence of internucleosomal fragmentation. $E M B O \quad J$. 12: 3679-3684.

50. Graeber TG, Osmanian C, Jacks T, et al. (1996) Hypoxia-mediated selection of cells with diminished apoptotic potential in solid tumours [see comments]. Nature 379: 8891.

51. Allday MJ, Sinclair A, Parker G, Crawford DH, Farrell PJ. (1995) Epstein-Barr virus efficiently immortalizes human $B$ cells without neutralizing the function of p53. EMBO J. 14: 1382-1391.

52. Allday MJ, Inman GJ, Crawford DH, Farrell PJ. (1995) DNA damage in human B cells can induce apoptosis, proceeding from Gl/S when p53 is transactivation competent and $\mathrm{G} 2 / \mathrm{M}$ when it is transactivation defective. EMBO J. 14: 4994-5005.

53. Balajee AS, May A, Dianov GL, Friedberg EC, Bohr VA. (1997) Reduced RNA polymerase II transcription in intact and perme- abilized Cockayne syndrome group B cells. Proc. Natl. Acad. Sci. U.S.A. 94: 4306-4311.

54. Selby CP, Sancar A. (1997) Human transcription-repair coupling factor CSB/ERCC6 is a DNA-stimulated ATPase but is not a helicase and does not disrupt the ternary transcription complex of stalled RNA polymerase II. J. Biol. Chem. 272: 1885-1890.

55. Friedberg EC. (1996) Cockayne syndrome-a primary defect in DNA repair, transcription, both or neither? Bioessays 18: 731-738.

56. Venema J, Mullenders LH, Natarajan AT, van Zeeland AA, Mayne LV. (1990) The genetic defect in Cockayne syndrome is associated with a defect in repair of UV-induced DNA damage in transcriptionally active DNA. Proc. Natl. Acad. Sci. U.S.A. 87: 47074711.

57. Leadon SA, Cooper PK. (1993) Preferential repair of ionizing radiation-induced damage in the transcribed strand of an active human gene is defective in Cockayne syndrome. Proc. Natl. Acad. Sci. U.S.A. 90: 10499-10503.

58. Han J, Sabbatini P, Perez D, Rao L, Modha D, White E. (1996) The ElB 19K protein blocks apoptosis by interacting with and inhibiting the p53-inducible and death-promoting Bax protein. Genes Dev. 10: 461-477.

59. Canman CE, Gilmer TM, Coutts SB, Kastan MB. (1995) Growth factor modulation of p53-mediated growth arrest versus apoptosis. Genes Dev. 9: 600-611.

60. Malcomson RD, Oren M, Wyllie AH, Harrison DJ. (1995) p53-independent death and p53-induced protection against apoptosis in fibroblasts treated with chemotherapeutic drugs. Br. J. Cancer 72: 952-957.

61. Polyak K, Waldman T, He TC, Kinzler KW, Vogelstein B. (1996) Genetic determinants of p53-induced apoptosis and growth arrest. Genes Dev. 10: 1945-1952.

62. Poluha W, Poluha DK, Chang B, et al. (1996) The cyclin-dependent kinase inhibitor p21 (WAF1) is required for survival of differentiating neuroblastoma cells. Mol. Cell. Biol. 16: 1335-1341.

63. Gorospe $M$, Cirielli $C$, Wang $X$, Seth $\mathrm{P}, \mathrm{Ca}-$ pogrossi MC, Holbrook NJ. (1997) p21(Waf1/Cip1) protects against p53-mediated apoptosis of human melanoma cells. Oncogene 14: 929-935.

64. Walker KK, Levine AJ. (1996) Identification of a novel p53 functional domain that is 
necessary for efficient growth suppression. Proc. Natl. Acad. Sci. U.S.A. 93: 15335-15340.

65. Ruaro EM, Collavin L, Del Sal G, et al. (1997) A proline-rich motif in p53 is required for transactivation-independent growth arrest as induced by Gasl. Proc. Natl. Acad. Sci. U.S.A. 94: 4675-4680.

66. Henning KA, Li L, Iyer N, et al. (1995) The Cockayne syndrome group A gene encodes a WD repeat protein that interacts with CSB protein and a subunit of RNA polymerase II TFIIH. Cell 82: 555-564.

67. Iyer N, Reagan MS, Wu KJ, Canagarajah B, Friedberg EC. (1996) Interactions involving the human RNA polymerase II transcription/ nucleotide excision repair complex TFIIH, the nucleotide excision repair protein XPG, and Cockayne syndrome group B (CSB) protein. Biochemistry 35: 2157-2167.

68. Yankulov K, Yamashita K, Roy R, Egly JM, Bentley DL. (1995) The transcriptional elongation inhibitor 5,6-dichloro-1-beta-D-ribofuranosylbenzimidazole inhibits transcription factor IIH-associated protein kinase. J. Biol. Chem. 270: 23922-23925.

69. Lu H, Fisher RP, Bailey P, Levine AJ. (1997)
The CDK7-cycH-p36 complex of transcription factor IIH phosphorylates p53, enhancing its sequence-specific DNA binding activity in vitro. Mol. Cell. Biol. 17: 5923-5934.

70. Milne DM, Campbell LE, Campbell DG, Meek DW. (1995) p53 is phosphorylated in vitro and in vivo by an ultraviolet radiationinduced protein kinase characteristic of the c-Jun kinase, JNK1. J. Biol. Chem. 270: 5511 5518.

71. Xia Z, Dickens M, Raingeaud J, Davis RJ, Greenberg ME. (1995) Opposing effects of ERK and JNK-p38 MAP kinases on apoptosis. Science 270: 1326-1331.

72. Zanke BW, Boudreau K, Rubie E, et al. (1996) The stress-activated protein kinase pathway mediates cell death following injury induced by cis-platinum, UV irradiation or heat. Curr. Biol. 6: 606-613.

73. Wang Y, Prives C. (1995) Increased and altered DNA binding of human $\mathrm{p} 53$ by $\mathrm{S}$ and G2/M but not G1 cyclin-dependent kinases. Nature 376: 88-91.

74. Price BD, Hughes-Davies L, Park SJ. (1995) Cdk2 kinase phosphorylates serine 315 of human p53 in vitro. Oncogene 11: 73-80.

Communicated by P. Chambon. Accepted October 15, 1997. 